\title{
HISTÓRICO DOS CURSOS SUPERIORES DE HISTÓRIA E DA FORMAÇÃO DOS PROFESSORES DE HISTÓRIA NO BRASIL (1931-1998)
}

\author{
Caio Corrêa Derossi ${ }^{53}$
}

\begin{abstract}
RESUMO: O presente ensaio teórico buscou refletir, a partir da literatura especializada, o histórico dos cursos superiores de História e as implicações com a formação de professores da área. Assim, em uma visada panorâmica, discutiu-se as trajetórias históricas de institucionalização do curso e da disciplina escolar ao longo do tempo, considerando suas particularidades, enfocando as relações com a formação docente, com as políticas públicas educacionais e com os ecos nas práticas pedagógicas.
\end{abstract}

PALAVRAS-CHAVE: Histórico dos cursos de História. Formação de professores de História. História da Educação.

\section{PALAVRAS INICIAIS}

O presente ensaio teórico, de natureza qualitativa e de abordagens bibliográfica e documental buscou, a partir de uma investigação na literatura especializada e em documentos de ordem legal, refletir sobre o processo histórico de formação de professores de História no Brasil. Para tanto, sabendo da multiplicidade de perspectivas de se compreender e analisar tal questão, em razão das (des)continuidades das trajetórias ao longo do tempo, optou-se por preconizar as tramas e teias históricas, por meio de uma visada panorâmica, em longa duração, discutindo os movimentos de institucionalização do curso superior de História, considerando os espectros social, político e econômico das distintas épocas, direcionando o debate até a contemporaneidade, com destaque para legislações e políticas públicas educacionais, no recorte dos cursos e da formação docente em História.

Por fim, o texto retorna à questão da formação de professores, de forma mais localizada nas implicações pedagógicas formativas e das práticas

53 Licenciado em História e Mestrando pelo Programa de Pós-Graduação em Educação, ambos da Universidade Federal de Viçosa (UFV).E-mail: derossi.caio@gmail.com. 
docentes. Tais relações, além de serem mediadas por documentos legais, currículos e políticas públicas que instauram uma miríade interpretativa entre ações, desejos e resistências, cabe destacar a histórica formação peculiar de professores segrega em blocos os conhecimentos específicos dos pedagógicos e/ ou entre as faculdades e departamentos de História e de Educação.

Destarte, tendo tal horizonte pela frente, composto por tantas outras dinâmicas anteriores, propõe-se a pensar de modo crítico os processos formativos no âmbito da instituição, bem como das modalidades inicial e continuada dos demais profissionais da educação, no caso específico, os professores de História. Portanto, à luz das referências especializadas e dos documentos legais pertinentes, serão discutidas, em uma perspectiva de longa duração, a institucionalização dos cursos de História e a formação docente para essa disciplina.

\section{DESENVOLVIMENTO}

Zamboni e Floresta (2008), refletindo sobre a formação dos professores de História, elencam que três pontos inseridos em uma trajetória temporal merecem atenção. O primeiro, relativo aos cursos de licenciatura em Estudos Sociais e História. O segundo se refere às relações dicotômicas impostas em relação às modalidades de licenciatura e bacharelado, bem como aos aspectos teóricos e práticos nos cursos de História. E, por último, as diretrizes legais e curriculares que regiam a formação de professores para a atuação na educação básica e as matrizes dos cursos de graduação em História. Portanto, o percurso que se pretende fazer nessa seção é interligar os aspectos trazido pelas autoras, visto o reconhecimento de sua ressonância atual, acrescentando elementos dos percursos históricos dos cursos de História e da formação de professores de História. A opção por trilhar esse caminho não fora calcada em um mero exercício de ilustração ou de entendimento de uma reação causa-efeito. Mas, por se entender que é relevante refletir sobre as questões históricas da disciplina e de seus profissionais, buscamos compreender as linhas de (des)continuidade e os possíveis pontos de toque com os sujeitos e contextos que compõem esse ensaio teórico.

Tal exercício pretendido, de compreender a partir de uma visada histórica, o local dos cursos de formação de professores de História, corroboram para que sejam entendidas como as determinadas questões colocadas por Zamboni e Floresta (2008) foram (re)significadas e permaneceram no tempo, como o par dito dicotômico teoria versus prática. Essa dicotomia se mostra presente de forma anterior à instalação dos cursos superiores de História, na terceira década do século XX, bem como nas reformulações e diretrizes legais propostas para a formação de professores e cursos de História em 1990, que retomam, por sua vez, as críticas feitas sobre as licenciaturas curtas em Estudos Sociais, nos anos 1970. Nesse sentido, Mesquita e Zamboni (2008, p. 130-162) defendem que, a 
partir da década de 70, prolongando-se pelos anos seguintes, travou-se uma luta pela formação de professores e pelo ensino de História, que se confundia com a criação da Associação Nacional de Professores Universitários de História (ANPUH), atual Associação Nacional de História, mantendo a mesma sigla e os empreendimentos contrários à ditadura civil-militar brasileira.

Em função do contexto político-social do país e da interlocução com personagens próximos da educação básica, durante as décadas de 1970 e 1980, a ANPUH lança a sua atenção para a formação dos professores de História. Por isso, Fonseca (2012) entende que o campo de estudos sobre o ensino e a formação de professores circunscritos na área de conhecimento histórico é recente e precisa de contínuos investimentos, diálogos e divulgação. Ferreira (2012) entende que, apesar de avanços nos estudos relacionados ao ensino de História, ainda se têm poucas produções que tratam da institucionalização da disciplina em contexto de ensino superior, o que representa uma possibilidade de investigação para os estudiosos do campo da História e da Educação. Logo, paralelamente aos pontos elencados por Zamboni e Fonseca (2008), o presente texto propõe discutir a criação dos cursos superiores em História no Brasil, as decisões do Conselho Federal de Educação (CFE) nos anos 1960 para a criação de um currículo para os cursos de História, as relações entre a formação em nível superior e a fundação da ANPUH, as graduações em Estudos Sociais e suas críticas e uma mirada nas políticas públicas curriculares para os cursos de História na atualidade.

Ferreira (2006), ao tratar da criação dos primeiros cursos de História no Brasil, aponta que, apesar do investimento de pesquisas em torno das universidades, pouco se debatera acerca de cursos específicos, privilegiando análises mais latas. Cabe destacar estudos como de Ferreira (1999; 2006; 2012), Lopes (2008; 2010), Roiz (2007) e Machado (2000), que se dedicaram a estudar cursos de História nas primeiras décadas do século XX, nos espaços do Rio de Janeiro e São Paulo. O Decreto $\mathrm{n}^{\circ} 19.852$, de 1931, contém um primeiro modelo sugestivo para os cursos de História proposto pela Universidade do Rio de Janeiro ${ }^{54}$. Apesar de não ter sido praticado, ele concebia uma habilitação conjunta em História e Geografia. Com a publicação do Estatuto das Universidades Brasileiras, no mesmo ano, observa-se a criação de duas novas universidades, encabeçadas por força dos governos locais: a Universidade de São Paulo (USP) em 1934 e a Universidade do Distrito Federal (UDF) ${ }^{55}$ em 1935. Lopes (2008, p. 115) afirma que:

54 A Universidade do Rio de Janeiro foi fundada em 1920. Com a reorganização governamental do Estado Novo Varguista em 1937, passou a ser denominada de Universidade do Brasil e, desde 1965, até os atuais dias, carrega o nome de Universidade Federal do Rio de Janeiro, em função da união de três instituições de ensino superior que já existiam: a Escola Politécnica, a Faculdade de Medicina e a Faculdade de Direito.

55 A Universidade do Distrito Federal (UDF) foi criada em 1935, período que a cidade do Rio de Janeiro era a capital do país. Idealizada por Anísio Teixeira, secretário de Educação na época, além de sediar cursos considerados tradicionais, tais como Direito, Engenharias e Medicina, contava com uma Faculdade de Educação, marcando uma formação específica para o magistério, em nível superior. Entretanto, durante o período do Estado Novo Varguista, em 1939, a UDF foi fechada e deslocados a estrutura e o pessoal para a Universidade do Brasil. 
apesar da existência de uma base comum entre a USP e a UDF, ambas constituídas como expressões do ideário contido no Manifesto dos Pioneiros e voltadas tanto para a pesquisa científica como para a formação de professores, a UDF, por incorporar a concepção educacional de Anísio Teixeira, demonstrava maior preocupação com o preparo do magistério, enquanto a USP resultava de um projeto articulado aos interesses da oligarquia paulista, menos afeita à formação profissional e mais voltada para a pesquisa desinteressada.

Ferreira (1999) avalia a criação da USP como uma reação da Revolução Constitucionalista de 1932, que manifestou a sua oposição à subida de Getúlio Vargas ao poder, em 1930, mesmo após a eleição de Júlio Prestes, candidato paulista. Assim, a instituição poderia contribuir com a retomada do prestígio e do poder político-econômico do estado, consolidado durante o período da Primeira República (1889-1930).

Fundada com o objetivo de oferecer um cabedal de conhecimentos humanísticos à elite, principalmente a agrária, a Faculdade de Filosofia, Ciências e Letras (FFCL) sediava o curso de História e Geografia e, conforme discute Nadai (1983), diferentemente das outras faculdades da instituição, a FFCL não se preocupava com uma formação direta para o trabalho. A USP também possuía o Instituto de Educação, que oferecia formação específica e profissional para os estudantes de licenciatura. Os cursos funcionavam no modelo " $3+1$ ", no qual os três primeiros anos eram destinados às disciplinas específicas e o último ano, às pedagógicas. Assim, após concluírem os três anos de bacharelado na FFCL, os alunos se dirigiam ao Instituto de Educação para realizar a formação profissionalpedagógica.

Roiz (2007), em seu trabalho que analisou vinte anos do curso de História e Geografia da USP, chega, em suas conclusões, ao entendimento de que a ênfase dada pelas matrizes curriculares giravam em torno, principalmente, das temáticas da História Mundial e da Geografia Física. Com o fechamento do Instituto de Educação em 1938, a FFCL incluiu as demandas pedagógicas e, portanto, concluindo o curso de Didática, o aluno receberia o título de licenciado.

A UDF era formada pelas Escola de Ciências, Escola de Economia e Direito, Escola de Filosofia e Letras, Instituto de Artes e Instituto de Educação, sendo este último voltado para a experimentação pedagógica. Ferreira (2006) entende que essa estruturação era bastante arrojada para a época, já que concebia, de forma associada, a formação profissional e a formação técnica. A autora ainda afirma que:

Na visão de Anísio Teixeira, a universidade devia estar voltada para a produção do saber, e não apenas para a difusão e conservação dos conhecimentos, pois isso os livros já faziam. Tratava-se não de preparar simplesmente técnicos e professores, mas de formar um novo tipo de 
profissional, iniciado na pesquisa científica e crente na ação diretiva da educação. O projeto da UDF pretendia ainda estimular a formação de um novo tipo de intelectual, capaz de atuar com competência numa sociedade técnico-científica e democrática e integrar os objetivos da universidade à vida pública e cultural do Rio de Janeiro e ao seu sistema de ensino básico. (FERREIRA, 2006, p.142)

Em função do projeto da UDF estar em consonância com o Manifesto dos Pioneiros da Educação de 1932, os pilares da pesquisa e do ensino estavam entrelaçados. Cabe destacar que o Manifesto foi apresentado no final do ano de 1931, na IV Conferência Nacional de Educação organizada pela Associação Brasileira de Educação. Publicado no ano de 1932, como uma obra coletiva fruto da contribuição de 26 personalidades do campo educacional, o documento defendia, entre outros pontos: a defesa do ensino superior e da formação docente, bem como de uma escola pública, laica, gratuita e de qualidade para todos.

A UDF ofertava um curso de formação para professores primários, e era a Escola de Economia e Direito a responsável pela formação de professores de História e de Geografia, que funcionava em um formato separado. Embora tenha sido ativo por quatro anos, o projeto do curso de História de duração de 3 anos contemplava, de forma conjunta, os conhecimentos específicos e os profissionais, e também os pedagógicos (LOPES, 2008). Entretanto, Ferreira (2011) e Lopes (2010) apontaram que, no decorrer do funcionamento do curso, existiam outras opiniões que preconizavam a formação pedagógica de forma separada. Nesse sentido, a partir do ano de 1937, os componentes pedagógicos passaram a figurar, de forma reduzida, no final do curso. Mas, com o acirramento do Golpe do Estado Novo (1937-1945) no mesmo ano, a situação da UDF ficava cada vez mais complexa, culminando em sua extinção no ano de 1939.

Nascimento (2013) entende que a UDF não estava alinhada aos interesses do Governo Federal, principalmente em relação à figura de Gustavo Capanema, ministro de Saúde Pública e Educação, já que, tempos antes da instauração do Estado Novo, fundou-se a Universidade do Brasil, também sediada na capital do país, na época o Rio de Janeiro. Sem a intenção do funcionamento de duas instituições públicas na mesma cidade e com o fechamento da UDF, todos os cursos e envolvidos foram transferidos para a Faculdade Nacional de Filosofia (FNFi), que, outrora, fora a Faculdade de Filosofia, Ciências e Letras da Universidade do Brasil. Assim, a FNFi foi fundada em 1939 e oferecia 11 cursos de bacharelado e licenciatura, nas áreas de: Filosofia, Letras e Pedagogia. Independentemente da área cursada, a disciplina de Didática era obrigatória para as licenciaturas, pois ela era a responsável pela formação pedagógica dos futuros professores.

No que se refere em específico ao curso de História, ele era atrelado ao de Geografia, o que Lopes (2010) compreendeu como uma perda das idiossincrasias de cada área. As disciplinas, históricas, eram distribuídas seguindo uma 
perspectiva cronológica e confirmava-se no curso uma organização da formação em " $3+1$ ": três anos de formação específica no campo disciplinar e um ano de estudos na área pedagógica. Tal estrutura perpetuava-se, já que, como apontado por Ayres (2005), o papel do professor deveria ser o do transmissor de conhecimentos, sendo tal arranjo formativo o suficiente para o cumprimento dessa função técnica.

Nesse sentido, desde a sua fundação em 1939, os cursos da FNFi da Universidade do Brasil foram referência e modelo a ser seguido por outras instituições. Nascimento (2013) destaca que, no ano de 1946, instala-se uma mudança para a obtenção dos títulos na FNFi. Embora não se tenha alterado as grades curriculares, os cursos de licenciatura e bacharelado em História e Geografia aumentaram em mais um ano, sendo o último destinado para se cursar disciplinas eletivas da instituição, após o cumprimento das matérias obrigatórias. Para a licenciatura, além da disciplina de didática e das práticas nos ginásios de aplicação de ensino secundários ${ }^{56}$, ainda deveria ser cursada a disciplina de Psicologia Educacional.

A análise realizada por Ferreira (2012) demonstra que esse novo formato denota uma insatisfação de geógrafos e historiadores em dividir um mesmo curso e representa uma busca por pesquisas e por valorização de conceitos próprios de cada área, uma vez que as disciplinas eram separadas para o ensino nos bancos escolares. Mas a divisão em definitivo só aconteceu próximo aos anos 1950. Nascimento (2013) entende que, de 1945 a 1964, existiu uma série de discussões importantes para o campo educacional que reverberaram pelos anos seguintes. Aproveitando o período de relativa democracia, haja vista o término do Estado Novo em 1945, ocorreram manifestações que retomavam os ideais do Manifesto dos Pioneiros da Escola Nova, bem como a aprovação da Lei de Diretrizes e Bases da Educação Nacional (LDB) em 1961, no governo de João Goulart (1961-1964).

Dentre os artigos da LDB, o $8^{\circ}$ e o $9^{\circ}$ indicam a criação do CFE, com as finalidades de propor currículos e sugestões para o ensino básico, bem como o superior. O CFE começa a funcionar em 1962, e Martins (2000, p. 21) o descreve como:

órgão público normatizador [cujas] decisões são tornadas públicas por meio de documentos relativos aos processos instaurados internamente. Tais processos são distribuídos para estudos e pareceres dos conselheiros,

56 O Ginásio de Ensino Secundário foi criado com a perspectiva de preparação dos alunos para o ensino superior, através do caráter formativo do curso ginasial, promulgado pelo Decreto-Lei nº. 4.244 de 1942. Dentre outras tipologias de ginásios, podem ser citados: o Ginásio de Aplicação, com a finalidade de formação de professores e de campo de estágio, respaldado pelo Decreto-Lei nº. 9.053 de 1946; o Ginásio Vocacional, com objetivo de orientação profissional, proposto pelo Decreto $n^{\circ}$. 38.643 de 1961; e os Ginásios Orientados para o Trabalho ou ainda Ginásios Polivalentes e/ou Pluricurriculares, que foram instituídos pela Lei $n^{\circ} .4 .024$ de 1961, a Lei de Diretrizes e Bases da Educação Nacional (LDB). Ver: HILSDORF, 2003; NUNES, 1980; TAMBERLINI, 2001. 
que posteriormente os apresentam para discussão da Câmara de Ensino a que estiver vinculado. Depois de aprovado na Câmara, o parecer do relator é enviado para conhecimento dos outros conselheiros, na Plenária Executiva (Pleno). Somente após aprovação no Pleno é que os resultados podem ser divulgados.

A autora ainda afirma que o CFE, nas suas configurações nas décadas de 1970 e 1980, dividia-se em duas câmaras: uma para o ensino superior e outra para a educação de $1^{\circ}$ e $2^{\circ}$ graus. A LDB de 1961 prescreveu que, em caso de ausência de professores habilitados, a admissão para os cargos seria através de exames de suficiência, o que fomentou ainda mais questionamentos da necessidade da formação em nível superior para o exercício do magistério. Nessa direção, percebeu-se uma lógica de suprir as demandas por docentes, entretanto com pessoal não qualificado para os cargos. Candau (1987) assinala que uma das causas para a falta de profissionais formados se dava pelas dificuldades no acesso às faculdades de formação de professores. A autora destaca que:

\begin{abstract}
De acordo com um Relatório do Inep, que utiliza dados referentes ao segundo semestre de 1949, o número total dessas faculdades no país é de 22, sendo 7 em universidades oficiais (Bahia, do Brasil, Minas Gerais, Paraná, Recife, Porto Alegre e São Paulo), 5 em universidades particulares, todas católicas (PUCs do Rio de Janeiro, Rio Grande do Sul, Campinas e São Paulo, esta última possuindo duas escolas), e 10 isoladas. (CANDAU, 1987, p. 15)
\end{abstract}

Assim, o quadro de pouca expansão e de concentração das Faculdades de Filosofia, para além do deficit formativo de profissionais como supracitado, acabou por fomentar e potencializar as diferenças e os descompassos nos processos de institucionalização dos cursos de formação de professores no Brasil. Enquanto nas cidades do Rio de Janeiro e São Paulo tais cursos começaram nas décadas de 1930, o trabalho de Aguiar (2010), que enfocou o estado de Santa Catarina, mostrou que as ações na região só começaram trinta anos depois, portanto na década de 1960. Já quando o estado da Paraíba é enfocado, Bezerra (2007) data o processo de institucionalização dos cursos de licenciatura entre os anos de 1949 e 1952. Essas exemplificações são compatíveis com os apontamentos de Candau (1987), que afirmou que os investimentos mais maciços na expansão das Faculdades de Filosofia ocorreram a partir da década de 1960, chamando a atenção, principalmente, para o crescimento vertiginoso da iniciativa privada que formava mais de $80 \%$ dos diplomados, através dos cursos normais e de outra natureza superior.

A separação dos cursos de História e Geografia aconteceu em 1955, através da Lei no ${ }^{\circ}$ 2.594, no governo de Café Filho (1955-1956). Mas algumas 
instituições, que já ofereciam as graduações pregressas à nova configuração, continuaram formando em conjunto geógrafos e historiadores até o início dos anos 1960. Nesse momento, tanto a Associação dos Geógrafos Brasileiros (AGB), fundada em 1934, quanto a Associação dos Professores Universitários de Histórias (ANPUH), hoje denominada como Associação Nacional de História, fundada em 1961, fizeram coro favorável à separação dos cursos em prol do trabalho, com as especificidades de cada campo. Sobre a ANPUH em específico, Martins (2000) retrata que era formada majoritariamente por professores da USP e da Universidade do Brasil, que se concentravam na produção e na partilha das pesquisas científicas, furtando-se ao debate, ou debatendo muito pouco as temáticas relativas ao ensino e à formação de professores.

Entretanto, Nascimento (2013) narra uma passagem na qual o ensino de História foi objeto central de análise: o fato ocorreu em 1962, com destaque para a participação da professora Maria Yedda Linhares, catedrática da Universidade do Brasil, em um evento da ANPUH. E uma das questões que emergiram era que, apesar da independência dos cursos em 1955, os currículos não mudaram, seguindo as diretrizes do final dos anos 1930. Portanto, mesmo com o horizonte formativo sendo marcado por cursos reputados, como o da USP e o da Universidade do Brasil, cada faculdade ofertava um tipo de currículo para a formação dos professores.

Nesse contexto, pautou-se pelo reconhecimento da necessidade de mudanças no ensino superior, para corresponder às demandas da sociedade e da expansão dos processos de escolarização, bem como para uma qualificada formação tanto do pesquisador quanto do professor. Diantes de tais discussões e devido às movimentações e encontros da ANPUH em 1962, o CFE, na figura do relator Newton Sucupira, propõe um novo currículo para os cursos de História. Segundo Nascimento (2013), a proposição baseou-se na diferenciação do papel do historiador e do professor de História, reconhecendo que ambos devam ter entendimento aprofundado da disciplina. Assim, o currículo ficou dividido em: uma parte específica comum; outra com as disciplinas pedagógicas; e uma terceira parte variável, de complementação, de acordo com as possibilidades oferecidas pela faculdade.

Destarte, mesmo com a atuação do CFE e das mudanças acerca da separação entre licenciatura e bacharelado, entende-se que persistiram as dicotomias formativas entre o ensinar e o pesquisar, entre os aspectos teóricos e práticos e os próprios cursos. Logo, em uma última instância, perdurou o modelo formativo do " $3+1$ ", que hipervalorizou os conhecimentos específicos em detrimento dos pedagógicos.

Com o golpe civil-militar, que depôs o presidente João Goulart em 1964, iniciava-se o período que durou 21 anos. Durante a ditadura civil-militar, mudanças relativas à legislação educacional aconteceram, ressaltando a Lei ${ }^{\circ}$. 5.540, de 1968, que reformou o Ensino Superior e, em 1971, foi homologada a Lei $\mathrm{n}^{\circ} .5 .692$, que modificava, em forma de complemento, a LDB, que estava 
em vigência. Nadai (1992) discute como as novas diretrizes legais impactaram na formação de professores através de cursos de curta duração, aligeirados e com conteúdo minorado. Tanto a História quanto a Geografia tiveram suas idiossincrasias negadas, uma vez que foram aglutinadas em uma disciplina única, os Estudos Sociais, que compunha os currículos do $1^{\circ}$ e do $2^{\circ}$ graus, sendo que, no $2^{\circ}$ grau, a carga horária fora reduzida. Desde a LDB de 1961, a previsão de exames de suficiência para profissionais sem a formação específica para docência já era normatizada e, em 1964, foi proposta a criação de cursos universitários polivalentes e de rápida duração, não só para área de Estudos Sociais, mas para também os campos das Letras e das Ciências.

Nascimento (2012) afirma que tais cursos tinham duração de três anos e formariam professores que atuariam no ginásio. Os cursos de Estudos Sociais preparariam os professores para atuarem na docência de História, Geografia, Organização Social e Política Brasileira (OSPB) e Educação Moral e Cívica (EMC). Quem fazia o curso de Letras estava habilitado para trabalhar com Língua Portuguesa e uma língua moderna estrangeira, como Inglês, Espanhol ou Francês, e as Ciências habilitavam para o trabalho com Biologia, Física, Química e Matemática. Cabe destacar que a criação de tais cursos se relacionavam com a expansão dos sistemas de ensino e a demanda por professores, principalmente nas localidades de interior, conforme apontou o parecer do conselheiro do CFE Newton Sucupira (1966). É válido sublinhar que, para além de um quadro de escassez de docentes, existiu a perseguição e a troca de professores, retirados de disciplinas das grades curriculares, como práticas recorrentes do período. Sobre os currículos dos cursos de Estudos Sociais, eles eram compostos de elementos de História, Geografia, Ciências Sociais e os conhecimentos pedagógicos. Com as mudanças legais em 1968 e 1971, mudanças curriculares foram alçadas para a disciplina de Estudos Sociais.

Um ponto específico que merece destaque é a disciplina de EMC. Criada em 1969, ela foi posta como matéria obrigatória em todos os níveis de ensino. $\mathrm{Na}$ educação superior, era oferecida na forma da matéria de Estudo dos Problemas Brasileiros (EPB), ministrada em dois períodos de todos os cursos ${ }^{57}$.

Assim, estipulou-se que a formação para a docência de EMC se daria em cursos superiores ou nos cursos normais, sendo que a primeira formação, as licenciaturas, habilitaria a atuação em escolas de nível médio e universitário e a segunda, os cursos normais, voltados para a atuação em escolas primárias (AGUIAR, 1975). Nascimento (2013) apontou que se chegou a cogitar uma formação universitária em separado para a disciplina de EMC, mas que, por questões funcionais, a formação em nível superior se dava junto ao curso de Estudos Sociais. Isso ocorria em função de uma pretensa proximidade entre a EMC e os Estudos Sociais, além de fomentar a formação dos professores polivalentes, habilitados para a atuação em várias disciplinas, chancelando os cursos de licenciaturas curtas e as perspectivas legais de 1968 e 1971. Destacou- 
se que, no mesmo período, foram pensadas as diferenças entre as licenciaturas curta e plena, sendo a segunda, a plena, mais alongada em tempo, em conteúdos e nos aspectos de pesquisa e de extensão, enquanto a primeira, a curta, mais aligeirada e diminuta em tempo e nos conteúdos para a aprendizagem.

A implicação desses tipos distintos de formação está relacionada com a atuação e com a perspectiva de uma escola dualista (BAUDELOT; ESTABLET, 1971), já que, para além do trabalho em segmentos específicos, formavam-se professores de forma precária para alunos de camadas populares e de docentes com cabedal teórico ampliado para as classes abastadas. Nascimento (2013) destacou que as ações do CFE em 1972 estipularam carga de 1.200 horas para as licenciaturas curtas de Estudos Sociais e de 2.200 horas para as licenciaturas plenas. O currículo era composto, como já citado, por temas de História, nas áreas de Histórias Antiga, Média, Moderna, Contemporânea e do Brasil, e de Geografias Física, Humana e do Brasil. Ambas as áreas não contemplavam estudos Regionais e das Américas. No campo de estudos das Ciências Sociais, a ênfase dada era em Sociologia e em Antropologia. Na Filosofia, o foco era concentrado nas discussões éticas e na Teoria Geral do Estado, com ênfase para a Ciência Política. As disciplinas pedagógicas eram: Psicologia da Educação, Didática, Funcionamento e Estrutura do Ensino e Práticas de Ensino. Esta última fazia parte do Estágio Curricular Supervisionado. Além disso, continha as disciplinas de EPB, como marca da presença da EMC no ensino superior, e de Educação Física, pois, desde 1971, tal disciplina deveria compor os currículos de todos os segmentos de ensino (AGUIAR, 1975).

Portanto, o curso de Estudos Sociais era composto por uma série de disciplinas das Ciências Humanas para a formação generalista do professor. As licenciaturas curtas em Estudos Sociais, que se iniciaram no ano de 1973 e se encerraram no ano de 1986, deveriam ser realizadas entre a duração de um ano e meio a quatro anos, visando o cumprimento das 1.200 horas. Os cursos coexistiram com a Licenciatura Plena em História e mantiveram seus currículos estruturalmente próximos da década de 1960 até os anos finais do século XX, data em que foram homologadas as Diretrizes Curriculares Nacionais (DCN's) para os cursos de História.

Monteiro (2002) apontou que, nas décadas de 1970 e 1980, o paradigma da racionalidade técnica imperou na formação dos professores, que eram entendidos como sujeitos aplicadores de técnicas rigorosas. Como as práticas de extensão e de pesquisa estavam caminhando de forma paulatina no Brasil, os cursos de licenciatura em História, no caso, debruçavam-se sobre as formações técnica, específica e pedagógica, esta última ligada à transmissão do conhecimento, como era entendido o papel do professor, sem maiores interlocuções entre os saberes, prevalecendo, portanto, a lógica do " $3+1$ ". Com o início da abertura política na década de 1980 e com o fim do Ato Institucional (AI) no 5, começaram a se registrar manifestações em prol da liberdade de expressão e por mudanças na ordem político-social. Assim, no ano de 1982, homologou-se a Lei $n^{\circ} 7.044$, que 
reformou os ensinos do $1^{\circ} \mathrm{e} 2^{\circ}$ graus. Nesse sentido, o ensino técnico obrigatório deixou de ser praticado no $2^{\circ}$ grau e amplos debates foram realizados acerca dos cursos de Estudos Sociais e da volta das disciplinas de História e de Geografia aos bancos escolares, bem como da própria formação de professores (MESQUITA; ZAMBONI, 2008).

Entretanto, segundo Nascimento (2013), na década de 1980, o CFE ainda entendia que os cursos de Estudos Sociais deveriam ser mantidos, porém foram feitas críticas às licenciaturas curtas. Ao fim, o que circulava na esfera governamental era a manutenção dos cursos de Estudos Sociais, com habilitações para os cursos de História e de Geografia, extinguindo as formações em separado, já que eram considerados avulsos. Tanto a ANPUH quanto a AGB manifestaramse rapidamente contrárias à extinção dos cursos e à manutenção das licenciaturas curtas. Glezer (1982) estudou à época as manifestações dos intelectuais sobre tais proposições, e os consensos encaminharam para a máxima de que as possíveis ações eram contrárias ao desenvolvimento científico e ao pluralismo de ideias. Fenelon (1984) registrou que a oposição mais sistemática aos Estudos Sociais e às licenciaturas curtas só ganharam mais força quando concursos públicos e o reconhecimento social entenderam como habilitados aqueles com formação em licenciatura plena em História e Geografia, por exemplo, em detrimento dos formados em licenciatura curta em Estudos Sociais. Martins (2000), na mesma direção de Fenelon (1984), registrou que a ANPUH fez uma oposição concisa quando, em 1976, os professores de História e de Geografia foram retirados do $1^{\circ}$ grau e ficaram restritos ao $2^{\circ}$ grau, reverberando, assim, na formação universitária já que a demanda fora reprimida. Nesse momento, a autora também revela que a maior preocupação voltava-se para as demandas por trabalho, tais como os modelos e currículos que deveriam ser ensinados.

Mesquita e Zamboni (2008) retrataram as manifestações dos historiadores e da ANPUH contra as licenciaturas de Estudos Sociais e os respectivos esforços dos professores universitários para construção de relatórios e documentos que traçassem um panorama dos cursos de História e a relevância da profissão na construção de uma ciência comprometida e responsável com as questões sociopolíticas do país. Esse posicionamento relacionava-se também com a formação de novos professores de História, de forma a correlacionar, em sua formação, o ensino e a pesquisa, implicados com as realidades as quais esses professores atuariam e, portanto, a uma História com vínculos nos problemas do presente, viva e em constante disputa. Nascimento (2013) ressalta o Congresso da ANPUH, realizado em 1984 na capital baiana, que gerou um documento que pedia o fim dos cursos de Estudos Sociais, da disciplina de OSPB, da volta das matérias e dos professores de História e Geografia em substituição aos Estudos Sociais para o $1^{\circ}$ e $2^{\circ}$ graus. Ainda na década de 1980, a reação das instituições de ensino superior foi a de ampliar a formação dos cursos de Estudos Sociais, tornandoos plenos, e transformar o currículo como equivalência de um ciclo inicial em História ou Geografia. Apenas com a nova LDB - Lei nº. 9.394, de 1996 -, as 
licenciaturas curtas foram extintas, postulando que a formação docente dar-se-á em cursos superiores, de licenciaturas plenas, com exceção para os profissionais da educação infantil e das séries iniciais, que poderiam ser formados nos cursos normais. Foi na década de 1990, com o clima social e democrático do país mais consolidado, que, além da LDB, foram criadas as Diretrizes Curriculares para os segmentos da educação básica e do ensino superior e os Parâmetros Curriculares Nacionais (PCN’s). Segundo Caimi (2001), é no período dos anos 1990 que os debates acerca da formação de professores reflexivos, investigativos e críticos a suas práticas, ganharam ressonância e reconhecimento fortuitos para refletir sobre os seus saberes e ações nos espaços escolares.

Como supracitado, foi no final dos anos 1990 que o Ministério da Educação (MEC) propôs a criação das Diretrizes Curriculares dos cursos de graduação. Nascimento (2013) retrata que, no caso específico dos cursos de História, em 1998, o MEC convoca a diretoria da ANPUH, bem como os historiadores Luzia Margareth Rago, da Universidade Estadual de Campinas (UNICAMP), Ciro Flamarion Cardoso, da Universidade Federal Fluminense (UFF), e Elizabeth Cancelli, da Universidade de São Paulo (USP), para compor uma comissão de criação das Diretrizes Curriculares Nacionais aprovadas pelo Conselho Nacional de Educação (CNE), na Câmara de Ensino Superior (CES), pelo Parecer 492, em 2001, e fixadas pela Resolução no 13 dos mesmos órgãos, no ano seguinte.

Uma das principais mudanças geradas pelas DCN's foi a atualização do currículo do curso de História, que fora estabelecido em 1962, período de franca expansão de oferta da graduação. Isso foi anterior aos progressos e às mudanças na forma de se pensar e construir o conhecimento histórico, que foram potencializados nos anos 1970 com a criação dos programas de pós-graduação em História no país. Portanto, as DCN's atualizaram os currículos e se aproximaram dos avanços científicos e de novas possibilidades de formação dos profissionais da área de História e de atuação, até então defasados em mais de 30 anos. O texto final alia as perspectivas de ensino, de pesquisa e de extensão, relacionando-as aos ofícios do historiador e do professor. Cabe ressaltar que, nas DCN's, a figura do historiador é mais trabalhada que a do professor, que é entendido como uma extensão ou continuidade da primeira formação, baseada nos conhecimentos específicos da História. Diferentemente dos entendimentos que se tinham nos anos 1970 e 1980, tal concepção que separava o professor do pesquisador oferecia ao docente uma formação que não propunha uma interface com a pesquisa. Nas Diretrizes, observa-se uma valorização da imagem do historiador ante a do professor. Um exemplo disso pode ser entendido através das habilidades e das competências a serem trabalhadas pelos estudantes da graduação em História, contidas no documento. As DCN's constituíram seis parâmetros gerais e apenas 2 são atribuídos como específicos para a licenciatura, referindo-se aos temas a serem ensinados e às metodologias para isso. Nesse mesmo sentido, embora identifiquemos os avanços com relação ao professor pesquisador e os avanços teórico-metodológicos da área, o texto das DCN’s não faz menção às escolas de 
educação básica e suas relações com a graduação em História e o destino dos egressos.

Quando comparado ao currículo de 1962, uma mudança entendida por Nascimento (2013) como importante foi a concentração das disciplinas sobre práticas de ensino nos cursos de História e não mais nos institutos, nos departamentos e nas faculdades de Educação. Ao passo que o autor observa como um ganho a formação mais específica e direcionada, na constituição e na consolidação de um campo de ensino e de pesquisa, cabe também refletir sobre a necessidade de docentes licenciados e que se dediquem ao estudo do Ensino de História para a realização de debates mais organizados.

Para o texto das Diretrizes, as práticas de ensino devem percorrer todo o curso de formação inicial, por toda a graduação. Pareando o currículo de 1962 e as DCN's, Nascimento (2013) destaca que, apesar das modificações e das atualizações, a estruturação de conteúdos continuou muito próxima, com eixos divididos sobre os estudos teórico-metodológicos da área, os que são relativos às grandes eras espaço-temporais e os considerados complementares. Especificamente para os cursos de licenciatura, ocorrem as disciplinas ora denominadas de práticas ou laboratórios de ensino, bem como os estágios. Embora as DCN's tratem da formação do professor pesquisador ante o paradigma da formação de docentes como técnicos, a figura do licenciado em História ainda era/é muito relacionada ao domínio dos saberes específicos do campo e do conhecimento de áreas afins, reforçando a ideia de pesquisa, diante dos conhecimentos pedagógicos em si. Destarte, sobre o professor da educação básica, as DCN's propõem um professor pesquisador, que ofereça ênfase ao processo de ensino-aprendizagem dos alunos, relacionando os aspectos sociais que eles trazem, visando o movimento de (re) pensar as próprias práticas. São as próprias dinâmicas envolvidas nos processos de construção de saberes pessoais e profissionais, advindas das experiências e das trajetórias de vida que vão auxiliar e corroborar as inserções acerca dos debates e das práticas como docente.

Villalta (1992) aponta que, nas décadas de 1980 e 1990, intensificam-se os debates acerca da formação de professores de História no Brasil. O autor desenvolve o texto a partir do par "professor real" e "professor ideal", refletindo sobre como a formação e a dicotomia colocada entre a teoria e prática podem gerar distanciamento em relação ao futuro local de trabalho do licenciado, reverberando também um estranhamento sobre o que se idealiza ser o papel do professor e sobre o que é praticado no cotidiano. Villalta (1992) ainda destaca que os cursos de História se organizam de forma estanque entre disciplinas que se ocupam a discutir teorias e metodologias, bem como são poucas as experiências que propiciam as discussões sobre ensino e práticas escolares.

Outro ponto que o historiador também levanta é o pouco diálogo entre departamentos e faculdades de História e Educação. Ele entende que a formação do professor acaba por se fazer precária em função da miséria teórica e da prática secundarizada. O que está no horizonte desejado é a formação de professores 
capazes de construir conhecimentos e repensar as práticas, aproximando-se dos textos legais que preconizam a interseção dos aspectos de pesquisa e de ensino na formação docente. Silva e Otto (2011) retrataram, a partir de suas experiências na docência universitária, como as disciplinas de práticas e de ensino são relevantes na formação de futuros professores e como elas podem ser concatenadas no currículo, em prol de potencializar discussões. Para Fonseca (2006, p. 23):

O historiador-educador ou o professor de História é alguém que domina não apenas os métodos de construção do conhecimento histórico, mas um conjunto de saberes e mecanismos que possibilitam a socialização deste conhecimento. "Saber alguma coisa não é mais suficiente para o ensino, é preciso saber ensinar."

Na mesma perspectiva, Rossato (2011, p. 89-90) afirma que:

Aprender História não é somente acumular uma sequência de fatos e processos passados. O aprendizado histórico envolve apropriarse de aspectos da epistemologia do fazer histórico, entre as quais a compreensão de conceitos do tempo, a identificação das evidências e de que estas são incompletas e limitadas como são limitadas e provisórias as explicações históricas. A partir dessa perspectiva, ensinar história não se restringe a ensinar narrativas históricas elaboradas pelos historiadores e organizadas em uma lista de conteúdos previamente definidos. Ensinar história é algo mais complexo, é ensinar a capacidade de pensar historicamente. Para isso, além dos conteúdos, devem ser desenvolvidas habilidades cognitivas que visem possibilitar que os indivíduos possam conhecer e explicar o mundo a partir das ferramentas próprias do saber histórico.

Portanto, a formação de professores de História, como disposto nos estudos e nos entendimentos legais supracitados, deve-se preocupar com a possibilidade de formação de conhecimentos através da reflexão e implicados com as maneiras que os interlocutores socializarão e se apropriarão de tais conhecimentos. Assim, nesse percurso, as histórias e trajetórias de vida pessoal e profissional se misturam e (co)formam os professores, suas pesquisas e suas práticas.

\section{CONSIDERAÇÕES FINAIS}

À guisa das considerações finais, o presente texto vislumbrou uma mirada histórica acerca dos processos de constituição dos cursos de História no Brasil 
e a formação do professor de História durante a passagem do tempo, com suas transformações, através dos movimentos legais e de associações representativas da área. Sobre os papeis do historiador e do professor de História, Fonseca (2011, p. 7) afirma:

\begin{abstract}
Dos historiadores espera-se que conheçam bem a historiografia, os pressupostos teórico-metodológicos que orientam seu trabalho, as técnicas de investigação, os procedimentos para o tratamento das fontes de pesquisa. Além de tudo isso, daqueles que são também professores de História, espera-se que conheçam os conteúdos, as práticas pedagógicas e os procedimentos didáticos. No entanto, não é usual esperar que eles conheçam, também, a história da disciplina que pesquisam ou que ensinam. Seria, porém, desejável que isso ocorresse.
\end{abstract}

Apesar dos avanços e dos acúmulos da pesquisa nas áreas de ensino e de formação de professores de História, um vasto caminho encontra-se a ser percorrido, já que, como apontado pelo texto, existem lacunas sobre os temas, bem como elementos afins relacionados às normatizações legais e à institucionalização dos cursos. O objetivo aqui foi o de oferecer uma vista panorâmica da institucionalização dos cursos superiores de História e da formação de professores para a área, já que, como aponta Hartog (1996), o ato de escrever, de fomentar respostas e perguntas sobre os tempos passado, presente e futuro, relaciona-se, assim, com as nossas questões de pesquisa, conosco e com outros personagens que deixam lastros anteriores, sendo produtores e produtos de construções históricas. Por isso, ao fim, depois desse exercício pontual de reflexão, pensando no compromisso de transformação social da educação e dos educadores, continuamos a escrever e a estudar sobre a formação de professores para contribuir com uma sociedade mais justa e menos desigual.

\title{
REFERÊNCIAS
}

AGUIAR, Letícia Carneiro. "A formação de professores catarinenses na década de 1960 e 1970: entre proposições e realizações”. In: JORNADA DO HISTEDBR, IX, 2010, Belém-PA. Trabalhos Completos... Campinas (SP): Histedbr, 2010. p.1-2.

AYRES, Ana Cléa B. M. "Tensão entre matrizes: um estudo a partir do Curso de Ciências Biológicas da Faculdade de Formação de Professores/UERJ”. 183 f. Tese (Doutorado em Educação) - Faculdade de Educação, UFF. Niterói (RJ), 2005. 
AZEVEDO, Fernando de. "A reconstrução educacional do Brasil. Manifesto dos Pioneiros da Educação Nova”. In: GONDRA, José G.; MAGALDI, Ana Maria (Org.) A reorganização do campo educacional no Brasil: manifestações, manifestos, manifestantes. Rio de Janeiro: 7Letras, 2003.

BAUDELOT, Christian \& ESTABLET, Roger. L'ecole capitaliste en France. Paris, Maspero, 1971.

BEZERRA, Francisco Chaves. "O ensino superior de História na Paraíba (19521974): aspectos acadêmicos e institucionais”. 140 f. Dissertação (Mestrado em História) - Universidade Federal da Paraíba. João Pessoa, 2007.

CAIMI, Flávia Eloísa. Conversas e Controvérsias: o ensino de História no Brasil (1980- 1998). Passo Fundo (RS): Ed. Universitária UFP, 2001.

CANDAU, Vera. Novos rumos da Licenciatura. Brasília: Inep, 1987.

CHAGAS, Valnir. Formação do magistério: novo sistema. São Paulo: Atlas, 1976.

DEROSSI, Caio Corrêa; HOLLERBACH, Joana D’Arc Germano. "A disciplina de Estudo dos Problemas Brasileiros (EPB) na Universidade Federal de Viçosa (UFV): Em foco o projeto educacional do regime civil-militar para as universidades brasileiras". Revista de História e Historiografia da Educação. Curitiba, v. 3, no 9, p. 152-173, setembro/dezembro de 2019.

FENELON, Déa. “A questão de Estudos Sociais”. In: ZAMBONI, Ernesta (Org.) A prática do ensino de história. São Paulo: Vozes; Cedes, 1984. p.13.

FERREIRA, Marieta de Moraes. "A trajetória de Henri Hauser: um elo entre gerações". In: NEVES, Lúcia Maria B. P. das; GUIMARÃES, Lúcia Maria P.; GONÇALVES, Márcia de A.; GONTIJO, Rebeca (Org.) Estudos de Historiografia Brasileira. Rio de Janeiro: Ed. FGV, 2011. p.237-259.

. "Notas sobre a Institucionalização dos Cursos Universitários de História no Rio de Janeiro". In: GUIMARÃES, Manoel Luiz Salgado (Org.) Estudos sobre a Escrita da História, Rio de Janeiro: 7Letras, 2006.

"O ensino da História na Faculdade Nacional de Filosofia da Universidade do Brasil”. História, Ciências, Saúde - Manguinhos, Rio de Janeiro, v.19, n.2, p.611- 636, abr.-jun. 2012.

. "Os professores franceses e o ensino da História no Rio de Janeiro nos anos 30". In: MAIO, Marcos Chor; VILLAS BÔAS, Glaucia (Org.) Ideais de Modernidade e Sociologia no Brasil: ensaios sobre Luiz de Aguiar Costa Pinto. Porto Alegre: Ed. UFRGS, 1999. v.1, p.277-299. 
FONSECA, Selva Guimarães. Caminhos da História ensinada. 11.ed. Campinas (SP): Papirus, 2010.

pesquisa

. "Formação de professores de História: reflexões sobre um campo de

(1987-2009)". Cadernos de História da Educação, Belo Horizonte, v.11, n.1, p.285303, jan.-jun. 2012.

. Ser professor no Brasil: História Oral de Vida. 3.ed. Campinas (SP): Papirus, 2006.

.; COUTO, Regina Célia do. "A formação de professores de História no Brasil: perspectivas desafiadoras do nosso tempo". In: FONSECA, Selva; ZAMBONI, Ernesta. Espaços de formação do professor de História. Campinas (SP): Papirus, 2008. p.101-130.

FONSECA, Thais Nivia de Lima e. História \& Ensino de História. 3.ed. Belo Horizonte: Autêntica, 2011. p.7.

GLEZER, Raquel. "Estudos Sociais: um problema contínuo". Revista Brasileira de História, São Paulo, v.2, n.3, p.117-149, mar. 1982.

HARTOG, François. "Tempo e História: como escrever a História da França hoje?”. História Social, Campinas (SP), n.3, p.127-154, 1996.

HILSDORF, Maria Lúcia Spedo. História da educação brasileira: leituras. São Paulo: Pioneira Thomson Learning, 2003, 135p

LOPES, Sônia de Castro. "A formação do professor de História na Universidade do Distrito Federal (1935-1939)". Educação em Foco, Juiz de Fora, v.15, n.2, p.111-134, set. 2010-fev. 2011.

"Um modelo autônomo e integrador de formação docente: a breve experiência da Universidade do Distrito Federal (1935-1939)". Revista Contemporânea de Educação, Rio de Janeiro, v.3, n.5, p.147-164, jan.-jun. 2008.

MACHADO, Mônica Sampaio. "A implantação da Geografia universitária no Rio de Janeiro." Scripta Nova (Revista Eletrônica de Geografia e Ciencias Sociales), n.69, p.1-18, ago. 2000.

MARTINS, Maria do Carmo. "A História prescrita e disciplinada nos currículos escolares. Quem legitima estes saberes?” 263 f. Tese (Doutorado em Educação) - Faculdade de Educação, Universidade Estadual de Campinas (Unicamp). Campinas (SP), 2000. 
MESQUITA, Ilka Miglio; ZAMBONI, Ernesta. "A formação de professores na trajetória histórica da Associação Nacional de História (Anpuh)". In: FONSECA, Selva; ZAMBONI, Ernesta. Espaços de formação do professor de História. Campinas (SP): Papirus, 2008. p.130-162.

MONTEIRO, Ana Maria. "Ensino de História: entre saberes e práticas". $256 \mathrm{f}$. Tese (Doutorado em Educação) - Departamento de Educação, PUC-Rio. Rio de Janeiro, 2002.

NADAI, Elza. "O ensino de História no Brasil: trajetória e perspectiva”. Revista Brasileira de História, São Paulo, v.13, n.25/26, p.143-165, set. 1992-ago. 1993.

"O projeto republicano de educação superior e a Universidade de São Paulo”. Revista de História, São Paulo, n.115, p.3-16, jul.-dez. 1983.

NASCIMENTO, Thiago Rodrigues. "Licenciatura curta em Estudos Sociais no Brasil: sua trajetória na Faculdade de Formação de Professores de São Gonçalo/ RJ (1973-1987)”. 236 f. Dissertação (Mestrado em História Social) - Faculdade de Formação de Professores de São Gonçalo, Universidade do Estado do Rio de Janeiro (Uerj). São Gonçalo (RJ), 2012.

NASCIMENTO, T. R. "A formação do professor de História no Brasil: percurso histórico e periodização". Revista História Hoje, vol. 2, número 4, 2013, p.265304.

NUNES, Clarice. Escola \& Dependência: $o$ ensino secundário e a manutenção da ordem. Rio de Janeiro: Achiamé, 1980

ROIZ, Diogo da Silva. "A institucionalização do ensino universitário de Geografia e História na Faculdade de Filosofia, Ciências e Letras da Universidade de São Paulo, entre 1934 e 1956". Agora, Santa Cruz do Sul (RS), v.13, n.1, p.65-104, jan.-jun. 2007.

ROSSATO, Luciana. "Formação docente inicial no curso de História na Universidade do Estado de Santa Catarina: experiências e reflexões sobre o ensino de História". In: SILVA, Cristiani Bereta et al. (Org.) Experiências de ensino de História no Estágio Supervisionado. Florianópolis: Ed. Udesc, 2011. p.89-90.

SILVA, Cristiani Bereta; OTTO, Claricia. "Ensaiar práticas e transforma-se pela experiência”. In: SILVA, Cristiani Bereta et al. (Org.) Experiências de ensino de História no Estágio Supervisionado. Florianópolis: Ed. Udesc, 2011. p.11-19. 
SUCUPIRA, Newton. "Parecer 106/66 do Conselho Federal de Educação. Currículo mínimo de Licenciatura em Estudos Sociais". Documenta, Rio de Janeiro, n.46, 1966.

TAMBERLINI, Ângela. Os Ginásios Vocacionais: a dimensão política de um projeto pedagógico transformador. São Paulo: Annablume: Fapesp, 2001

VILLALTA, Luiz Carlos. "Dilemas da relação teoria e prática na formação do professor de História: alternativas em perspectiva”. Revista Brasileira de História, São Paulo, v.13, n.25/26 p.223-232, set. 1992-ago. 1993.

ZAMBONI, E.; FLORESTA, S. Espaços de formação do professor de História. Campinas: Editora Papirus, 2008.

\section{DOCUMENTOS:}

AGUIAR, José Márcio de (Org.) CFE - Pareceres Básicos: Reforma - Ensino de $1^{\circ}$ e $2^{\circ}$ graus. Brasília: MAI Ed., 1975.

BRASIL. Diretrizes Curriculares Nacionais para a Formação de Professores da Educação Básica, em nível superior, curso de licenciatura, de graduação plena. Disponível em: http://portal.mec.gov.br/index.php?option=com_ content\&view=article\&id=12991. Acessado em janeiro de 2020.

BRASIL. Parecer CNE/CES n 492, de 3 abr. 2001. Aprova as Diretrizes Curriculares Nacionais dos cursos de Arquivologia, Biblioteconomia, Ciências Sociais Antropologia, Ciência Política e Sociologia, Comunicação Social, Filosofia, Geografia, História, Letras, Museologia e Serviço Social. Disponível em: http:// portal.mec.gov.br/index.php?option=com_content\&view=article\&id=12991. Acessado em janeiro de 2020.

BRASIL. Resolução CNE/CES no 13, de 13 mar. 2002. Estabelece as Diretrizes Curriculares para os cursos de História. Disponível em: http://portal.mec.gov.br/ index.php?option=com_content\&view=article\&id $=12991$. Acessado em janeiro de 2020. 


\title{
HISTORY OF HIGHER HISTORY COURSES AND THE FORMATION OF HISTORY TEACHERS IN BRAZIL (1931-1998)
}

\begin{abstract}
This theoretical essay sought to reflect from the specialized literature the history of higher education courses in History and the implications for the training of teachers in the area. Thus, in a panoramic view, the historical trajectories of institutionalization of the course and school discipline were discussed over time, considering their particularities, focusing on the relationship with teacher training, with public educational policies and with echoes in pedagogical practices.
\end{abstract}

KEYWORDS: History of History courses. History teacher training. History of Education.

\section{HISTORIA DE CURSOS DE HISTORIA SUPERIOR Y LA FORMACIÓN DE PROFESORES DE HISTORIA EN BRASIL (1931-1998)}

RESUMEN: Este ensayo teórico buscó reflejar de la literatura especializada la historia de los cursos de educación superior en Historia y las implicaciones para la formación de docentes en el área. Así, en una vista panorámica, las trayectorias históricas de institucionalización del curso y la disciplina escolar fueron discutidas a lo largo del tiempo, considerando sus particularidades, enfocándose en la relación con la formación docente, con las políticas educativas públicas y con ecos en las prácticas pedagógicas.

PALABRAS CLAVE: Cursos de Historia de la Historia. Formación de profesores de Historia. Historia de la educación. 